\title{
AINT NO SENSE PROJECT (BOY IN THE BACK SEAT)
}

\section{Walter Anderson}

Three kids out driving in a car

Not doin much, not going far

Couple of shots blast out of nowhere

Blue lights flashing and sirens blare

Boy in the backseat barely a teen

Two in front three years older

Cops force 'em off on to the shoulder

But can't find a weapon on the scene

Big brain detectives can’t figure it out

Covered by an eclipse of doubt

District Attorney does the lazy and lame

Boy in backseat gets the blame

Snap your fingers fast as that

The Boy gets sentenced to the max

Didn't matter what were the facts

Here's your bunk complete with rats

Driver and shotgun they just lied

Signed document DA supplied

Boy in backseat completes the picture

Case is closed and made a fixture

Five years then into his sentence

A little bigger a little stronger

Just must say it can't be wronger

Stolen was his adolescence

Ten years pass and boy is a man

Sometimes dreams of Yucatan

He does not smoke he does no dope

Outside friends smuggle in some hope

Year fifteen he still keeps steady

Reading law books makes him heady

Somehow his story gets attention

On NPR his name they mention

Now it's been twenty since life was wrecked

But case is now an Innocence Project

Their noble cause needs our support

It's Boy in the Backseat's last resort 